\title{
Modeling Commodity Prices, Inflation And Monetary Policy Response
}

Punita Rao, University of Mumbai, India

\begin{abstract}
Inflation is generally defined as the rate of change of some price index. Well known examples are the Consumer Price Index, Wholesale Price Index and the personal consumption expenditure price Index. Measurement and forecasting of these indices has been a subject of ongoing debate and research in recent years. This paper attempts to contribute to the debate within the limits of an empirical and country specific. Section 1 deals with the transmission of Monetary policy to growth. Section 2 examines a simple model of inflation forecasting. Section 3 addresses the unfinished debate on Prices and Monetary management.
\end{abstract}

Keywords: Inflation, CPI, WPI, Monetary Policy

\section{INTRODUCTION}

nflation targeting is one of the major concerns for monetary policy in which central banks attempts to set
inflation on a declared target- typically by adjusting the interest rates. Interest rates and inflation tend to be inversely related and due to the declared or projected rate being known the likely moves of central banks to raise or lower interest rates become more transparent. If inflation appear to be above target, the central bank is likely to raise interest rates. This usually (but not always) has the effect over time of cooling the economy and bringing down inflation. If inflation is to be below target, the bank is likely to lower the interest rates. This usually (but not always) has the effect overtime to accelerate the economy and raising inflation. Under this policy investors know what the central bank considers the target inflation to be and therefore may more easily factor in likely interest rate changes in their investment choices. Central bankers need to be able to measure and forecast inflation as best as they can. Forecasting is particularly important, given the fact that monetary policy operates with "long and variable lags" and therefore policymakers need to act well in advance of actual developments in inflation. Inflation is generally defined as the rate of change of some price index. Well known examples are the Consumer Price Index, Wholesale Price Index and the personal consumption expenditure price Index. Measurement and forecasting of these indices has been a subject of ongoing debate and research in recent years. This paper attempts to contribute to the debate within the limits of an empirical and country specific. Section 1 deals with the transmission of Monetary policy to growth. Section 2 examines a simple model of inflation forecasting. Section 3 addresses the unfinished debate on Prices and Monetary management.

\section{TRANSMISSION OF MONETARY POLICY}

Monetary policy impulses travel to output, employment and inflation through a number of channels. While these channels are not mutually exclusive, the relative importance of these channels may differ from country to country depending on a number of factors including the underlying characteristic of the country, state of financial developments and the instruments of monetary policy. Broadly the vehicles of monetary policy can be classified into financial market prices (interest rates, exchange rates yield, assets prices), or financial market quantities (money supply credit aggregates foreign denominated assets). The interest rates channel emerges as a dominant transmission mechanism of monetary policy; it induces movements in other assets prices to generate wealth effects, in terms of market valuation of financial assets and liabilities. Higher interest rates induces an appreciation of the domestic currency which in turn, leads to a reduction in net exports and hence in aggregate demand and output. Monetary policy can also operate on aggregate demand through changes in the availability of loanable funds (i.e. the credit channel). 
The issue of the appropriate real interest rates for India has acquired a growing focus with the shift away from planned economy to a market economy in the context of financial sector reforms. The principal wedge between real and nominal interest rates is inflation expectations. In practice, the real interest rates is measured as inflation adjusted nominal interest rates but this is an ex post assessment of how inflation has eroded the returns on investment in some past period. To obtain a forward looking ex-ante measure, the real interest rate defined as nominal interest rate less inflationary expectations. Accordingly, the first step towards obtaining a forward looking view of the real interest rate is to estimate inflation expectations. A variety of approaches has been employed to model inflation expectations like drawing inferences from macroeconomic data, observing differences in yields of nominal and indexed bonds, etc The real interest rate calculated by adjusting the representative nominal interest rate for inflation expectations would diverge from an ex-post measure depending upon the volatility of the inflation rate. The main operating instrument for central bankers today is the short term interest rate. Markets are the deepest in the short end allowing central bankers to intervene in support of policy objectives without generating serious repercussions on the market activity. Moreover, impulses from the short-end are transmitted relatively quickly across the term structure of interest rates and this makes for efficiency in intervention. The recent experience has shown that central bankers have been proactively moving target interest rate in support of output and employment and financial stability, even if this has led to a temporary departure from their commitment to price stability.

Along with the bank rate, open market operations of the central bankers have also been actively used. With the central bank's stance to move away from the sector specific refinance schemes, liquidity in the system is managed increasingly through the liquidity Adjustment Facility (LAF), which was introduced in June 2000. the operating procedure of the LAF including auction methods and periods are being refined periodically to make it more efficient. As such the repo and revere repo rates emerging from the LAF auctions reflect the market conditions of availability of liquidity in the system along with the rate at which the liquidity is available from the Central Bank. The LAF injects/ absorbs liquidity on a day to day in a flexible manner and in the process provides a corridor for the call money and other short term interest rates... The interest rates, particularly at the short end, of the market, are more aligned and integrated. The economic agents are currently responding to changes in the interest rates. Nevertheless, there are quite a few rigidities in the structure of interest rates

In India, an abiding faith in the working of the credit channel of policy transmission runs through the conduct of monetary policy right from the 1950's. Monetary policy settings in the 1970's was in the direction of credit settings as an integral element of developing planning. Selective credit controls were strengthened by the institution of Credit Authorization Scheme and with the nationalization of banks The conduct of monetary management has undergone significant changes in the 1990's in terms of the objectives framework and instruments. The monetary stance in recent years has been to ensure that all legitimate requirements for credit are adequately met consistent with the objectives of price stability. Liquidity operations are conducted with a view to ensuring the demand for reserves is stable and adequately satisfied so that credit projections consistent with the macroeconomic objectives of growth and inflation are achieved. Simultaneously progressive instruments in the modes of the delivery of the banks credit have been pursued.

\section{A SIMPLE MODEL OF INFLATION}

Inflation is generally defined as a rate of change of some price index. More generally, price indexes are designed for a certain purpose and have optimal properties for that purpose, but they may not be well suited for others. Monetary policy needs measure of inflation, but it may well be that indexes designed to measure the value of a basket of commodities, or to convert nominal consumption goods into real consumption goods. In fact, policymakers have come to use variants of both the CPI and WPI, the so called core measure. The intuition behind these measure is that monetary policy is interested in broad and persistent movements in inflation and that certain price series being too volatile, introduce nose in the measurement of these broad movements, therefore the troublesome series(fuel, food and energy)are removed altogtherfrom the price index. Recently a lot of importance is assigned to headline inflation as a measure of inflation to incorporate sudden inflationary spikes for monetary management

We introduce a simple mode on lines with Burdekin and Sikkos (1999), that an AR (1) model of inflation, augmented with other variables adequately explains the evolution of inflation over long period of time. In an AR (1) 
model, inflation persistence is estimated by the coefficient on the lagged inflation rate from the following expression.

$\pi_{\mathrm{t}}=\alpha_{1}+\alpha_{2} \Omega_{\mathrm{t}-1}+\mu_{\mathrm{t}}$

where $\pi_{t}$ is the annual rate of inflation and $\alpha_{2}$ is the measure of inflation persistence. Both WPT and CPI are used to estimate the inflation phenomenon in India, from 1980-81- 2006-07.

WPI

$\pi_{\mathrm{t}}=0.542+0.761 \Omega_{\mathrm{t}-1}$

(2.34) (3.21)

$\mathrm{R}^{2}=0.451, \quad$ D.W. $=2.38$

CPI

$\Omega_{\mathrm{t}}=0.362+0.634 \Omega_{\mathrm{t}-1}$

$\mathrm{R}^{2}=0.432, \quad$ D.W. $=1.88$

There is a considerable difference in the persistence measure between the WPI and CPI. While levels of inflation persistence remain positive over the year, but estimate of $\alpha_{2}$ appear to oscillate between positive and negative values with reference to monthly data on CPI. Clearly this reinforces the view that inflation is easier to forecast when it is persistence than when it fluctuates between inflation and deflation. An important argument in modern macroeconomics is that economic "shocks" that is unexpected movements in economic variables create fluctuation in economic activity. If inflation is more difficult to forecast than unexpected movements are likely to take place. This is of course, no more than an argument for stability in the movement of prices and not advocating a particular level of prices which is beyond the scope of this paper.

An AR(1) model while useful as a descriptive device, is hardly a complete model of inflation. The evidence is preliminary and the results used to be augmented with encompassing tests to generate the best model in statistical terms. Essentially we retain the AR(1)framework but augment it with additional determinant assumed to be exogenous. This modified expression is written as

$\Omega_{\mathrm{t}}=\alpha_{1}+\alpha_{2} \Omega_{\mathrm{t}-1} \beta(\mathrm{L}) \mathrm{X}_{\mathrm{t}}+\mu_{\mathrm{t}}$

where all the variables are defined in equation (1) $\quad \beta(\mathrm{L})$ is the distributed lag function and Xt is the vector of exogenous function. In our model we use the term spread as a proxy for financial innovations. A maximum of 2 and.5 lags was considered on the yield of government dated securities. From our estimates the CPI was a better forecast for inflation at the short end and the WPI was better at the long end, which suggests financial innovations could represent a proxy for long run influences while several of the remaining factors would serve as a short run determinant.

$\Omega_{\mathrm{t}}=\alpha_{1}+\alpha_{2} \Omega_{\mathrm{t}-1} \beta\left(\mathrm{R}_{\mathrm{t}}-\mathrm{r}_{\mathrm{t}}\right)+\mu_{\mathrm{t}}$

CPI -short

$\pi_{t}=0.319+0.543 \Omega_{t-1} 0.897\left(R_{t}-r_{t}\right)$

$(0.821) \quad(2.096) \quad((2.430)$

$\mathrm{R}^{2}=0.468, \quad \mathrm{D} \cdot \mathrm{W} .=1.644$. 


$$
\begin{aligned}
& \text { CPI - long } \\
& \Omega_{\mathrm{t}}=0.321+0.460 \Omega_{\mathrm{t}-1} 0.671\left(\mathrm{R}_{\mathrm{t}}-\mathrm{r}_{\mathrm{t}}\right) \\
& \begin{array}{lll}
(0.921) \quad(2.109) \quad((3.451)
\end{array} \\
& \mathrm{R}^{2}=0.470, \quad \text { D.W. }=1.688 . \\
& \text { WPI - short } \\
& \Omega_{\mathrm{t}}=0.216+0.372 \Omega_{\mathrm{t}-1} 0.430\left(\mathrm{R}_{\mathrm{t}}-\mathrm{r}_{\mathrm{t}}\right) \\
& (0.650) \quad(1.682) \quad((7.631) \\
& \mathrm{R}^{2}=0.455, \quad \text { D.W. }=1.639 \text {. } \\
& \text { WPI - long } \\
& \Omega_{\mathrm{t}}=0.210+0.563 \Omega_{\mathrm{t}-1} 0.977\left(\mathrm{R}_{\mathrm{t}}-\mathrm{r}_{\mathrm{t}}\right) \\
& \text { (0.519) (3.34) ((4.07) } \\
& \mathrm{R}^{2}=0.672, \quad \text { D.W. }=2.14
\end{aligned}
$$

Further we can also estimate a version of equation 1 that mixes forward looking and backward looking behaviour along the lines suggested by Fuhrer (1997), on measuring and forecasting inflation. This approach extends the intuition that lies behind the use of core measure of inflation in that it takes us to further research on the measurement and forecast of inflation that is beyond the scope of this paper.

\section{PRICE MOVEMENTS AND MONETARY MANAGEMENT}

Price stability during the eighties was only short-lived, the price level began to rise from Jan 1983 onwards, and inflation was the result of the increase in the prices of certain items, like pulses, oilseed and other foodstuffs and increase in administered prices of a number of goods like coal, electricity cement, iron and steel. The government was prompt in taking measures from both the demand and supply side. On the demand side the monetary authority made a series of adjustment in the cash reserve ratio of the commercial banks to check the growth of liquidity in the banking system, banks were also asked to confine their lending operations within certain limits. Public expenditure was also reduced by 3 to 5 percent, imposed a temporary ban on government recruitment. The objective of monetary and fiscal measures was to check the flow of money supply and the check effective demand. On the supply side government attempted to increase the supply of goods and services through both short term and long term measures.

The inflation rate during the nineties was almost engineered by the government itself through rise in administered prices and indirect taxes. The inflationary pressures concentrated in primary commodities rose rapidly and the annual average rate of inflation in the early 90's was to the tune of 10.3 percent. But a few years from then inflation was controlled because of better performance in the agriculture sector and macroeconomic correction adopted by the government including reduction in the fiscal deficit. Since mid 1990's inflationary trends has eased and there has been a noticeable fall in the rate of increase in the prices of primary goods.

It is well recognized that inflation in India is a structural as well as a monetary phenomenon. With huge surge in capital inflows, the liquidity management with its underlying implications for inflation has been a major challenge to policy makers. The Whole sale Price Index continues to be the post popular measure of headline inflation as indicated in our study in the previous section. Wholesale Price Index has been rising since 2000 due to the increase in the prices of food articles like wheat and edible oils and mineral oils. The increase in international prices necessitated an upward revision in the prices of petrol and diesel in the domestic market. The increase in the prices of wheat pulses was largely due to supply side effects rather than demand side effects. The fiscal, administrative and monetary measures that were initiated in the early and late1990's started working through in terms of decline in the inflation. With a decline in the prices of the primary articles, deceleration was also observed 
in CPI. The deceleration became apparent in the later part of 2000.WPI recorded an inflation of 3.9 percent in Jan 2008, down sharply from the 6.3 percent inflation rate a year ago. Build-up of inflation in the fiscal year (end March 2007- Jan 2008) at 3.2 percent was also significantly lower than the inflationary build up of 5.9 percent in the corresponding period of previous year.

From a long term perspective, however inflation as measured in terms of WPI and CPI seems to be converging. Reconstructing the WPI and CPI, including the GDP consumption deflator with a common 1999-2000 base, reveals that the cumulative increase in inflation during the year 1999-2000 to 2006-2007 was highest for the Wholesale Price Index. There, however, were inter-year variations in the rate of inflation based on these indices. But, over the years the difference seems to be narrowing considerably. General converging of overall indices, measuring changes in prices notwithstanding their year-on-year variations, indicates a strong association in inflation, both in its acceleration and deceleration phase across all indices.

There is, however, no aggregate broad based CPI in India. While considering shifting the present base of CPI- UNME, the Technical Advisory Committee on Statistics of Prices and Cost of Living in the $44^{\text {th }}$ meeting, decided that (1) the resources proposed to be utilized of revision of CPI-UNME may be used for compilation of the CPI numbers separately for rural and urban areas and (2) .existing series of CPI-UNME may be continued without revision till CPI (urban) series gets stabilized. This step has already been initiated by the Central Statistical Organization.

The year 2006-07 was marked by a surge in headline inflation, volatility in the financial markets and the sizable swings in the liquidity. In spite of hardening of interest rates, the industrial sector was buoyant, leading to rapid expansion in non-food credit. The high level of capital inflows led to surge in the net foreign exchange assets from the RBI, had implication for rupee liquidity in the system. In response changes were made in the repo and reverse - repo rates. The RBI articulated the monetary policy stance in 2007-08 in accordance with the Annual Policy Statement of April 2007.The policy recognized the need to manage the transition to higher growth path while at the same time containing inflationary pressures.

\section{CONCLUSIONS}

To sum up, we find that though money is an important determinant of inflation in India, it is not the only factor affecting aggregate and relative prices. More important is to note that money supply itself is growing on account of government budget deficit caused by structural imbalance in the growth process. It appears that a mere reduction in money supply may reduce inflation rate, if at all, only at the expense of income, output, and growth. In the light of this view, we an attempt was made to examine an appropriate measure to explain inflation persistence, measure the inflation rate. It is observed that in the years to come inflation is likely to remain moderate. Moderate inflation, is thus, not a state that the economy can stay indefinitely without a firm government commitment to prevent further increase in inflation- a point that needs to be understood in the present Indian context, as the inflation rate is already in the moderate phase.

\section{REFERENCES}

1. Bhattacharya, B.B (1987) "The Effectiveness of Monetary Policy in Controlling Inflation the Indian experience. Prajan.

2. Bernake, Ben S (1983) "Non- Monetary Effects of the Financial crisis and the, Propagation of the great Depression”. American Economic Review. 73.

3. Bryan, Michael F, S. C. Cecchetti (1983) “ The Consumer Price Index as a Measure of Inflation”. NBER working paper no.4505. October.

4. $\quad$ Fisher Irving (1907) "The Rate of Interest: Its Nature Determination and Relation to Economic Phenomena". New York. McMillan.

5. $\quad$ Fisher. E.F (1986) “Indexing ,Inflation and economic Policy” The MIT Press Cambridge.

6. Fisher, Jonas. D. M. Chin, and R. Zhou (2002). "When can we forecast Inflation". Economic Perspective, Vol 20, No.1 First Quarter. 
7. Krugman Paul (1998) “Its Back Japan Slump and the return of the Liquidity trap'. Brooking Papers on Economic Activity, No. 2.

8. Fuhrer Jeffry (1997) "The (UN)Importance of Forward Looking Behaviour in Price Specification". Journal of Money Credit and Banking. August

9. $\quad$ Hagger, A. J(1964).” The Theory of Inflation" A Review, Melbourne University Press Australia.

10. Raj. K.N. (1966) 'Price behaviour in India. Indian Economic Review.

11. Reddy Y.V.(1998). "Interest Rates in India, Status and Issues". Reserve Bank of India Bulletin, July.

12. Reserve bank of India (2000) 'Handbook of Statistics'

13. Sargent Thomas (1969) 'commodity prices Expectations and Interest rates' Quarterly Journal of Economics

14. Shumway. R. H. (1998) “Applied Statistical Time Series Analysis”. Prentice hall, New Jersey.

15. Wurgler. J. (2000). "Financial Markets and the Allocation of Capital"' Journal of Financial Economics, Vol. 58.

\section{NOTES}

